Avaiable online at www.babglajol.info

Bangladesh J. Sci. Ind. Res. 43(2), 145-158, 2008
BANGLADESH JOURNAL OF SCIENTIFIC AND INDUSTRIAL RESEARCH

E-mail: bjsir07gmail.com

\title{
Effect of Ethylene Diamine Tetra Acetic Acid (EDTA) on the Surface Reaction Behavior and the Hydrogen Evolution Efficiency of Ni-30at.\%Cu Electrode in Alkaline Medium
}

\author{
A. K. M. Fazle Kibria \\ Chemistry Division, Atomic Energy Centre, P.O. Box-164, Ramna, Dhaka-1000, Bangladesh
}

\begin{abstract}
The surface reaction characteristics, hydrogen evolution efficiency and hydrogen evolution reaction kinetics of Ni-30at.\%Cu electrode have been investigated in 30wt.\% KOH electrolyte in presence and absence of ethylene diamine tetra acetic acid (EDTA) at room temperature by cyclic voltammetric technique. Cyclic voltammogram of the electrode showed three couples of oxidation-reduction peaks in between the potential range -1.1 to $+0.4 \mathrm{~V}$. The peak couples were originated from the electrochemical transformations of $\mathrm{Ni}(0) \leftrightarrow \mathrm{Ni}(\mathrm{OH})_{2}, \mathrm{Cu}(0) \leftrightarrow \mathrm{Cu}(\mathrm{I})$ and $\mathrm{Cu}(\mathrm{I}) \leftrightarrow \mathrm{Cu}(\mathrm{OH})_{2}$. An interference of the adsorped hydrogen over $\mathrm{Cu}(0)$ surface on the transformation of $\mathrm{Ni}(\mathrm{OH})_{2} \rightarrow \mathrm{Ni}(0)$ was found. It was realized that added EDTA forms Cu-EDTA complex over the electrode surface. With increasing the amount of EDTA, the thickness of $\mathrm{Cu}(\mathrm{OH})_{2}$ layer gradually decreased. Addition of $0.04 \mathrm{~g}, 0.08 \mathrm{~g}$ and 0.12g EDTA increased the hydrogen evolution efficiency of the electrode more than $6 \%, 12 \%$ and $17 \%$. Tafel plots for both the systems showed two well-defined Tafel regions. 0.12g EDTA increased the exchange current density $\left(i_{o}\right)$ values 1.3 times for both the Tafel regions. The observed $i_{o}$ value for the high overpotential $(\eta)$ region is 1.8 and 2.9 times higher than those of $\mathrm{Ni}$ and $\mathrm{Cu}$ electrodes. The Tafel slope (b) values for both the low and high $\eta$ regions are smaller than those observed for without EDTA system and also for the Ni electrode. From the achieved information, it can be concluded that addition of EDTA remarkably increased the hydrogen evolution efficiency of the Ni-30at.\%Cu electrode. It seems that hydrogen evolution reactions (HER) followed like mechanisms in absence and presence of EDTA.
\end{abstract}

Keywards: Ni-30at.\%Cu electrode, EDTA, Electrochemical transformation, Surface reactions, Hydrogen evolution, Hydrogen evolution reactions (HER)

\section{Introduction}

Hydrogen is considered to be an ideal energy carrier in the foreseeable future. It can be produced in pure form by water electrolysis and can be converted into useful energy 
without detrimental of environment (Kreuter and Hofman 1998, Aki et al. 2006, Kaninski et al. 2006). Hydrogen production is the basic cathodic reaction of water electrolysis. For the optimization of this reaction, the essential prerequisite is the selection of a cathode material. A cathode should exhibit good hydrogen evolution efficiency, be stable in electrolyte and available. Because of the low availability and high cost of noble metals, the choice of cathode materials recently confined to low cost transition metals (Jaksic et al. 1998). Investigations on $\mathrm{Ni}$ (Choquette et al. 1990), Kibria et al. 1995) and nickel based electrodes like $\mathrm{Ni}-\mathrm{Fe}(\mathrm{Hu}$ and Wu 1993), Ni-Co (Chi et al. 2006), NiZn (Giz et al. 1990), Ni-Mo (Raj and Venkatesan, 1988) have been going on in alkaline electrolyte medium for more than a decade. This electrolyte medium is preferred because of its better material corrosion inhibition property than the acidic medium during hydrogen evolution reactions (HER) (Kreysa et al. 1986, Choquette et al. 1990).

The hydrogen evolution study of Ni-Cu alloy is unknown. Considering the general relationship of $d$-electrons and hydrogen evolution capability of metals (Jaksic et al. 1998), this alloy can be a good electro-catalyst for the HER because of having at least $\mathrm{d}^{8}$ electrons in them. On the other hand, $\mathrm{Cu}$ is a cheap material and available. Moreover, it has higher corrosion resistance capability than Fe. Recently, authors (Brossard and Marquis, 1994) have reported 90\% exchange current density value of $\mathrm{Co}$ for $\mathrm{Cu}$. For a Co40at.\%Cu cathode about 5.0 and 4.5 times higher exchange current density value than those of pure $\mathrm{Cu}$ and $\mathrm{Co}$ have also been reported. The investigated $\mathrm{Co}-\mathrm{Cu}$ electrode was prepared by their electro-deposition over a nickel wire. As Co and Ni electrodes show almost similar hydrogen evolution efficiency, it is reasonable to assume that addition of $\mathrm{Cu}$ with Ni may increase the electrocatalytic activity for HER. Cu is known easily soluble in $\mathrm{Ni}$ and forms solid solution. In this situation, the newly exposed $\mathrm{Ni}$ atoms in $\mathrm{Cu}$ and vice versa may gain capability to increase the hydrogen evolution efficiency (Jaksic et al. 1998).

In order to lower the cost of electrode as well as the electrolyzer, the aim of the most current investigations is to find out the hydrogen evolution efficiency and to understand the hydrogen evolution reaction mechanism (HER) in presence of additives those have capability to modify the electrode surface and therefore the electrolysis efficiency. It has been observed that additive ethylene diamine tetra acetic acid (EDTA) is capable to modify the surface of Pd electrode (Jaksic et al. 1993). EDTA and thiourea have found effective in modifying the iron oxide electrode (Periasamy et al. 1996). Both the EDTA and Co-tris complex have improved the hydrogen evolution capability of noble metal electrodes (Vandenberg and Johnson, 1993). In this context, the present study program has been taken to investigate the sur- 
face reaction behavior and kinetics, the hydrogen evolution efficiency and hydrogen evolution reaction kinetics of $\mathrm{Ni}-30 \mathrm{at} . \% \mathrm{Cu}$ electrode in presence and absence of dissolved additives EDTA in alkaline electrolyte.

\section{Materials and Methods}

$\mathrm{Ni}$ and $\mathrm{Cu}$ of purity 99.9wt.\% purchased from the Tanaka Precious Metal Company, Japan, were used to prepare the $\mathrm{Ni}-\mathrm{Cu}$ alloy. Ni-30at.\%Cu alloy ingot was prepared by non-consumable arc melting and cooling. It was then annealed for $5 \mathrm{~h}$ at $973 \mathrm{~K}$ in a vacuum of about $1.3 \times 10^{-4} \mathrm{~Pa}$. The annealed ingot was then rolled into a sheet of $1 \mathrm{~mm}$ thickness and cut into square size to prepare the working electrode. For collecting electrode current, a Ni wire was spot welded vertically with the sheet and then insulated by a glass pipe and epoxy resin. The geometric surface area of the electrode was $0.59 \mathrm{~cm}^{2}$. A sheet of nickel of geometric surface area $9.25 \mathrm{~cm}^{2}$ was prepared to use as counter electrode. Both the working and the counter electrode surfaces were then freed from oxides if any by chemical etching. The electrode surfaces were then polished with 0.3 $\mu \mathrm{m}$ alumina paste and rinsed with distilled water. The used electrolyte was $30 \mathrm{wt} . \% \mathrm{KOH}$ solution. It was prepared from reagent grade $\mathrm{KOH}$ pellets and distilled water.

A three-electrode cylindrical electrochemical cell constructed in the laboratory was used for the experimental measurements. About
$100 \mathrm{ml}$ of the electrolyte was placed into the cell. The working, counter and $\mathrm{Hg} / \mathrm{HgO} . \mathrm{OH}-$ reference electrodes were then immersed in the electrolyte in triangular ways. The reference electrode consists of a luggin capillary. The capillary end of this electrode was kept about $2 \mathrm{~mm}$ apart from the surface of the working electrode. Before carried out any experiment, the electrolyte was freed from dissolved oxygen by bubbling $\mathrm{N}_{2}$ gas.

Cyclic voltammetric measurements were carried out by EG\&G PARC Model 362 potentiostat/Galvanostat and voltammograms were sketched by potential-current recorder EG\&G PARC Model RE 0089. The working electrode was activated before recording the voltammetric information of its surface reaction. To understand the mechanism of the growth and removal of hydroxide layers over the electrode surface, voltammetric information were carried out at various potential ranges ranging from $-1.1 \mathrm{~V}$ to $+0.4 \mathrm{~V}$ with and without EDTA. To evaluate the kinetics of the growth of hydroxide layers over the electrode surface, it was continuously cycled up to a long period and then voltammograms were sketched at different sweep rates ranging from $5 \mathrm{mV} / \mathrm{s}$ to 200 $\mathrm{mV} / \mathrm{s}$. The hydrogen evolution currents of the electrode were measured in between the potential range $-1.4 \mathrm{~V}$ to $-0.2 \mathrm{~V}$ by increasing the negative potential from - $1.1 \mathrm{~V}$ towards negative potential direction with a rate of $0.01 \mathrm{~V}$ at the scan rate of $10 \mathrm{mV} / \mathrm{s}$ under stirring condition. The kinetic parame- 
ters for the hydrogen evolution reactions, i.e., Tafel slope $(b)$ and exchange current density value at zero overpotential $\left(i_{o}\right)$ were evaluated from the logi ( $i=$ current density) vs. $\eta$ (overpotential) plot known as Tafel plot. The experiments were carried out at room temperature within $\pm 1^{\circ} \mathrm{C}$ error limit.

\section{Results and Discussion}

Figure 1 shows the cyclic voltammograms obtained for the activated $\mathrm{Ni}-30$ at\%Cu electrode in oxygen free electrolyte in the potential range $-1.1 \mathrm{~V}$ to $+0.4 \mathrm{~V}$ at different time periods after addition of $0.04 \mathrm{~g}$ EDTA in the electrolyte at the potential scan rate 100 $\mathrm{mV} / \mathrm{s}$. The electrode activation was carried out at the potential - $1.1 \mathrm{~V}$ for 20 minutes and then the voltammograms were recorded starting from - $1.1 \mathrm{~V}$. The voltammograms are clearly representing the effect of cycling on the oxidation-reduction behavior of the electrode surface. It can be seen that the voltammograms exhibited three oxidation peaks designed as pa1, $\mathrm{pa}_{2}$ and $\mathrm{pa}_{3}$ and three reduction peaks $\mathrm{p}_{\mathrm{c} 1}, \mathrm{p}_{\mathrm{c} 2}$ and $\mathrm{p}$ c3. A new peak represented by $\mathrm{p}_{\mathrm{c} 1}$ * with a high intensity appeared within 10 minutes. The potentials of the peaks pa1 and pc1 are coincided with those reported for $\mathrm{Ni}(0) \leftrightarrow \mathrm{Ni}(\mathrm{OH})_{2}$ transformations in alkaline medium (Kibria et al. 1995, Giz et al. 1990) and indicating their origin from the oxidation of $\mathrm{Ni}(0)$ to $\mathrm{Ni}(\mathrm{OH})_{2}$ and then its reduction to $\mathrm{Ni}(0)$. The oxidation of $\mathrm{Ni}(\mathrm{OH})_{2}$ to $\mathrm{NiOOH}$ occurs at around 0.48 V (Kibria and Mridha, 1996).
The chosen positive terminal potential is not enough to achieve such a transformation. So, it can be realized that the rest two oxidation peaks were originated due to the two step transformations of copper as $\mathrm{Cu}(0) \rightarrow \mathrm{Cu}(\mathrm{I})$ and $\mathrm{Cu}(\mathrm{I}) \rightarrow \mathrm{Cu}(\mathrm{OH})_{2}$. Considering the position of the rest three reduction peaks, it can be said that the peak pa2 and pc2, and pa3 and pc3 are couple of oxidation-reduction peaks. Peaks $\mathrm{p}_{\mathrm{c} 3}$ and $\mathrm{p}_{\mathrm{c} 2}$ are originated from the reduction of $\mathrm{Cu}(\mathrm{II}) \rightarrow \mathrm{Cu}(\mathrm{I})$ and $\mathrm{Cu}(\mathrm{I}) \rightarrow$ $\mathrm{Cu}(0)$. The peak pc1* seems originated due to the adsorption of hydrogen over the $\mathrm{Cu}(0)$ surface.

It can be seen that current for all the peaks gradually increased with time. But the increase in current for $\mathrm{Ni}(\mathrm{OH})_{2} \leftrightarrow \mathrm{Ni}(0)$ transformations is very small. Moreover, hydrogen adsorption over $\mathrm{Cu}(0)$ surface severely hinders the reduction of $\mathrm{Ni}(\mathrm{OH})_{2} \rightarrow$ $\mathrm{Ni}(0)$. It caused to decrease the hydrogen adsorption region that might be an obstacle to obtain vigorous hydrogen evolution reactions in the chosen potential range. It may be seen that peak couple of $\mathrm{Cu}(0) \leftrightarrow \mathrm{Cu}(\mathrm{I})$ transformations showed almost reversible behavior whereas those of $\mathrm{Cu}(\mathrm{I}) \leftrightarrow \mathrm{Cu}$ (II) transformations showed irreversible trend. However, increase in oxidation-reduction currents with time is representing the gradual increase in thickness of $\mathrm{Cu}(\mathrm{OH})_{2}$ layer over the electrode surface and its removal on the reverse scan. A complete study on the oxidation-reduction behavior informed that increase in thickness of this layer continued up to a period of about 120 minutes and then 


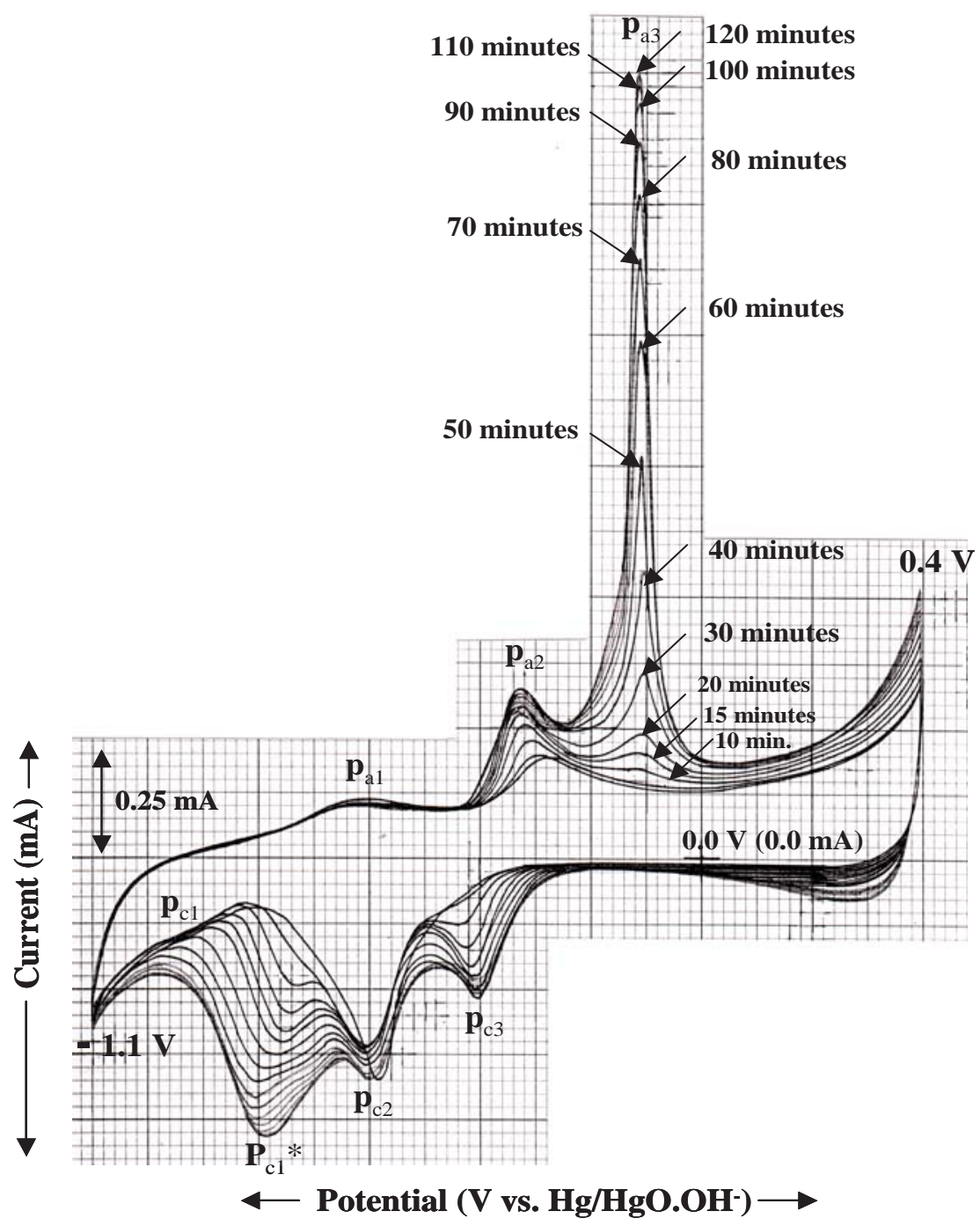

Fig. 1. Cyclic voltammograms of $\mathrm{Ni}-30 \mathrm{at} \% \mathrm{Cu}$ electrode in $30 \mathrm{wt}$ \% $\% \mathrm{KOH}$ electrolyte in presence of $0.04 \mathrm{~g}$ EDTA in between the potential range - $1.1 \mathrm{~V}$ to $0.4 \mathrm{~V}$ at different period of time at the potential scan rate $100 \mathrm{mV} / \mathrm{s}$.

became saturated. Formation of the saturated layer is indicating its stable position in the used electrolyte. It can be seen that increase in current for $\mathrm{Cu}(\mathrm{I}) \rightarrow \mathrm{Cu}(\mathrm{II})$ transformation up to 20 minutes is small. After that a sharp increase in peak current is indicating some irregularity in electrode surface reaction kinetics. In order to find out the fact, surface redox behaviors were recorded at various scan rates ranging from $5 \mathrm{mV} / \mathrm{s}$ to $100 \mathrm{mV} / \mathrm{s}$. 
Figure 2 shows the peak current $\left(i_{p}\right)$ vs. root of scan rate $\left(v^{1 / 2}\right)$ relationships of the $\mathrm{Cu}(0)$ $\rightarrow \mathrm{Cu}(\mathrm{I})$ and $\mathrm{Cu}(\mathrm{I}) \rightarrow \mathrm{Cu}(\mathrm{II})$ transformation steps. It can be seen that $i_{p}$ vs. $v^{1 / 2}$ followed linear relationship for both the reaction steps but that of $\mathrm{Cu}(\mathrm{I}) \rightarrow \mathrm{Cu}(\mathrm{II})$ is not passing through the origin. It informs that this reaction step is not purely diffusion-controlled. Such a reaction behavior of the electrode surface was also observed before the addition of EDTA which will be described below.
$\% \mathrm{Cu}$ electrode in the potential range - 1.1 $\mathrm{V}$ to $+0.4 \mathrm{~V}$ at different time periods without addition of EDTA in the electrolyte at the potential scan rate $100 \mathrm{mV} / \mathrm{s}$. In this case, saturation of hydroxide layer was achieved after 250 minutes. This time is about 2.1 times higher compared to that required to form saturated hydroxide layer with the EDTA system. It can be seen that the surface oxidation-reduction behaviors are analogous to those appeared with EDTA

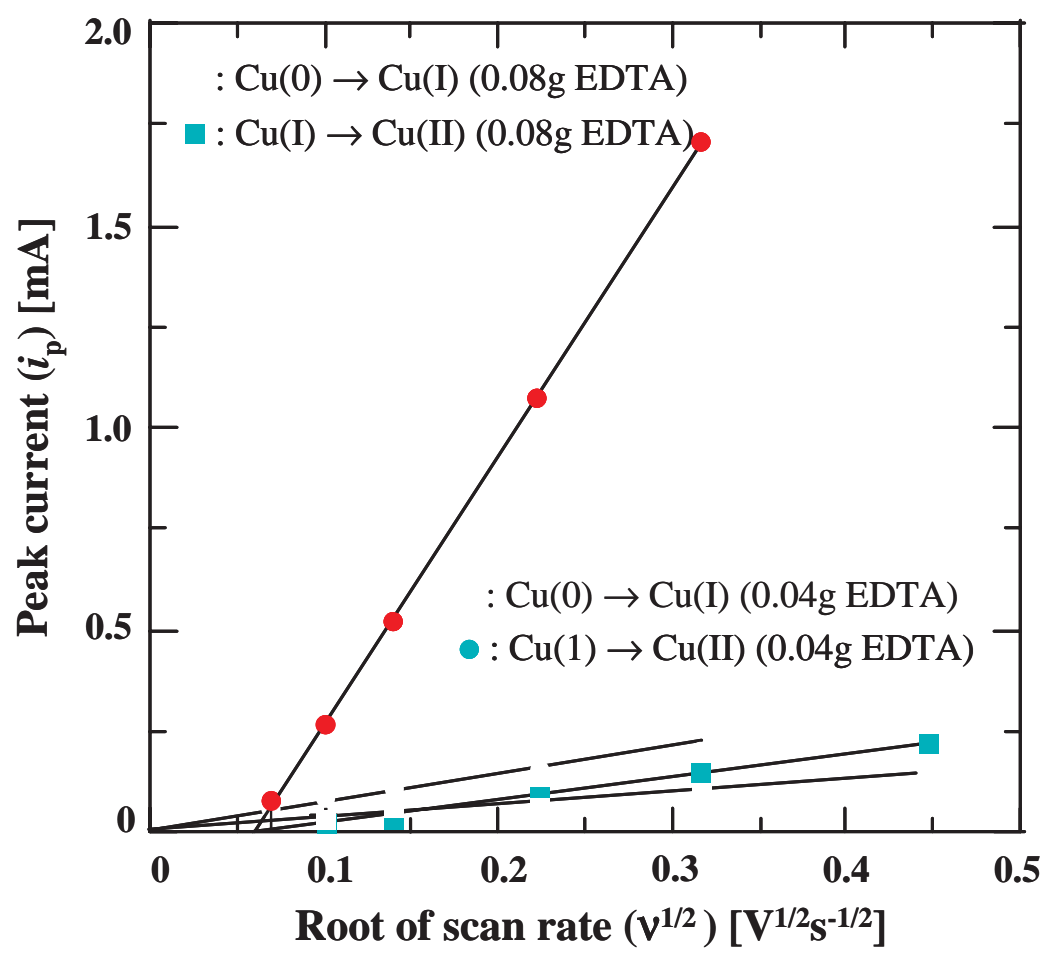

Fig. 2. Peak current $\left(i_{p}\right)$ vs. root of scan rate $\left(v^{1 / 2}\right)$ relationships for the oxidation steps $\mathrm{Cu}(0) \rightarrow$ $\mathrm{Cu}(\mathrm{I})$ and $\mathrm{Cu}(\mathrm{I}) \rightarrow \mathrm{Cu}(\mathrm{II})$ occurred over the Ni-30at.\% $\mathrm{Cu}$ electrode surface in presence of $0.04 \mathrm{~g}$ and $0.08 \mathrm{~g}$ EDTA.

Figure 3 shows a part of the cyclic voltammograms obtained for the activated Ni-30at
(Figure 1). But the peak currents are higher specially for the peaks those are related to 
$\mathrm{Cu}(\mathrm{I}) \rightarrow \mathrm{Cu}(\mathrm{II})$ transformation and adsorption of hydrogen over the $\mathrm{Cu}(0)$ surface. For the EDTA system, currents for these peaks at 60 minutes are about $1.0 \mathrm{~mA}$ and $0.18 \mathrm{~mA}$, respectively. These values are only $60.6 \%$ and $46.9 \%$ to those appeared without EDTA system at the same period of time. It indicates that EDTA highly interfering and concurrently suppressing the $\mathrm{Cu}(\mathrm{I}) \rightarrow \mathrm{Cu}(\mathrm{II})$ transformation reaction by forming $\mathrm{Cu}-$ EDTA complex. Obviously it formed complex with a fraction of $\mathrm{Cu}(\mathrm{II})$ generated over

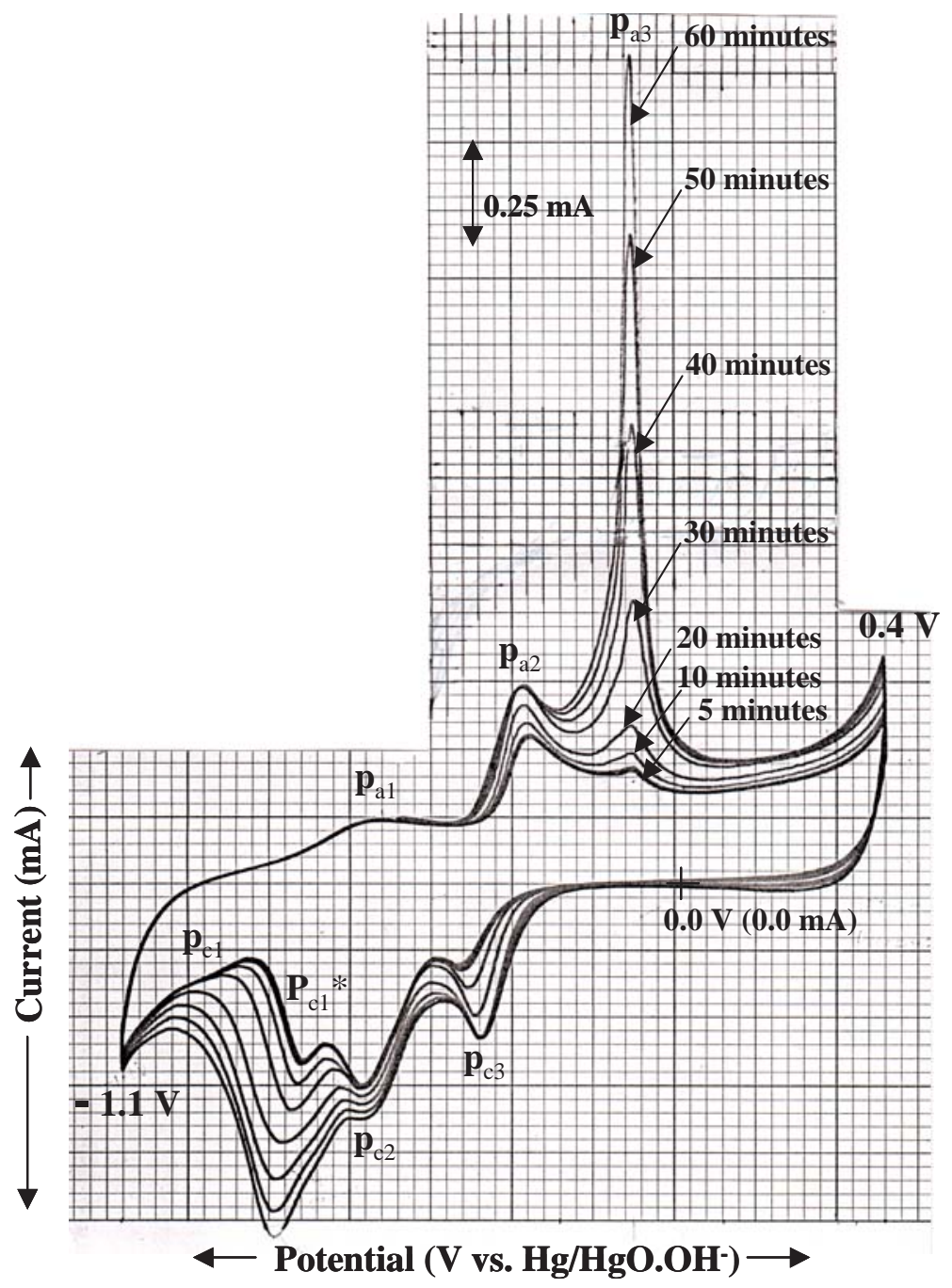

Fig. 3. Cyclic voltammograms of $\mathrm{Ni}-30 \mathrm{at} \% \mathrm{Cu}$ electrode in $30 \mathrm{wt}$ \% $\mathrm{KOH}$ electrolyte in between the potential range $-1.1 \mathrm{~V}$ to $0.4 \mathrm{~V}$ at different period of time at the potential scan rate $100 \mathrm{mV} / \mathrm{s}$. 
the electrode surface. The complex seems remained intact with the surface without disturbing the other redox transformations. As a result, the fraction of exposed $\mathrm{Cu}(0)$ surface decreased and hence the current for adsorption of hydrogen over the $\mathrm{Cu}(0)$ surface decreased. It may be seen that due to the addition of EDTA, the hydrogen adsorption region moved to - $0.97 \mathrm{~V}$ from - $1.0 \mathrm{~V}$, i.e., it allowed to extend the hydrogen adsorption region $30 \mathrm{mV}$ towards positive potential direction within 60 minutes. It is representing a good signal for getting better hydrogen evolution using EDTA (Jaksic et al. 1993). However still the reduction of $\mathrm{Ni}(\mathrm{OH})_{2} \rightarrow$ $\mathrm{Ni}(0)$ hindered by the hydrogen adsorption step of $\mathrm{Cu}(0)$.
In order to obtain more detailed information about the effect of EDTA on the $\mathrm{Cu}(\mathrm{I}) \leftrightarrow$ $\mathrm{Cu}(\mathrm{II})$ transformations and hydrogen evolution, 0.04g EDTA was added further in the electrolyte after getting saturated $\mathrm{Cu}(\mathrm{OH})_{2}$ layer over the surface within 120 minutes. Figure 4 shows the effect of this addition on the surface reactions as well as saturated $\mathrm{Cu}(\mathrm{OH})_{2}$ layer at the potential scan rate 100 $\mathrm{mV} / \mathrm{s}$. It can be seen that current for the $\mathrm{Cu}(\mathrm{I}) \rightarrow \mathrm{Cu}(\mathrm{II})$ transformation sharply decreased to $0.35 \mathrm{~mA}$ from $1.7 \mathrm{~mA}$ within 5 minutes and then reached to $0.17 \mathrm{~mA}$ at 35 minutes. At this state, current for the hydrogen adsorption over $\mathrm{Cu}(0)$ surface is only $0.08 \mathrm{~mA}$ which is $45 \%$ to that appeared at the saturated state while 0.04g EDTA was added

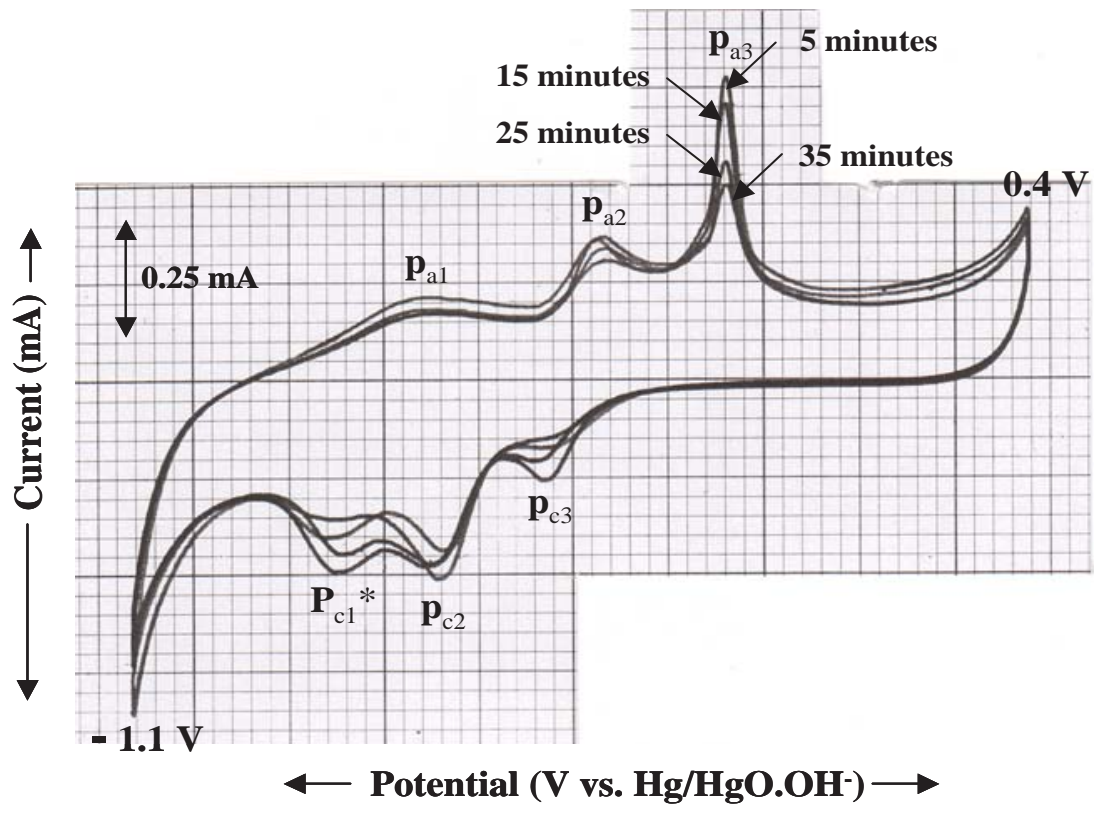

Fig. 4. Cyclic voltammograms of Ni-30at.\%Cu electrode in 30wt.\% KOH electrolyte in presence of further 0.04g EDTA in between the potential range $-1.1 \mathrm{~V}$ to $0.4 \mathrm{~V}$ at different period of time at the potential scan rate $100 \mathrm{mV} / \mathrm{s}$ after 120 minutes of cycling. 
(Figure 1). The hydrogen adsorption region further moved to - $0.90 \mathrm{~V}$ from - $0.97 \mathrm{~V}$. The hydrogen evolution efficiency seems a little higher. At this situation no noticeable reduction of $\mathrm{Ni}(\mathrm{II}) \rightarrow \mathrm{Ni}(0)$ is observed. It may be seen that currents for $\mathrm{Cu}(\mathrm{I}) \leftrightarrow \mathrm{Cu}(\mathrm{II})$ transformations moved towards equality. At this stage, it is reasonable to assume that the surface reaction behavior might be different from that showed earlier when only $0.04 \mathrm{~g}$ EDTA was added. In order to understand the fact clearly whether addition of further $0.04 \mathrm{~g}$ EDTA has changed the surface reaction kinetics or not, the surface redox behaviors are recorded at various scan rates ranging from $10 \mathrm{mV} / \mathrm{s}$ to $200 \mathrm{mV} / \mathrm{s}$. Peak current $\left(i_{p}\right)$ vs. root of scan rate $\left(v^{1 / 2}\right)$ relationships of the $\mathrm{Cu}(0) \rightarrow \mathrm{Cu}(\mathrm{I})$ and $\mathrm{Cu}(\mathrm{I}) \rightarrow \mathrm{Cu}(\mathrm{II})$ transformation steps are plotted and included in Figure 2. It may be seen that $i_{p}$ vs. $v^{1 / 2}$ for both the reaction steps again followed linear relationship but that of $\mathrm{Cu}(\mathrm{I}) \rightarrow \mathrm{Cu}(\mathrm{II})$ is not passing through the origin. This behavior is quite similar to that appeared before the addition of EDTA and after addition of $0.04 \mathrm{~g}$ EDTA. It informs that EDTA has no capability to change the electrode surface reaction trend. It can decrease the thickness of hydroxide layer by forming Cu-EDTA complex. Addition of EDTA can increase the hydrogen evolution efficiency of Ni-Cu electrode by moving the hydrogen adsorption region towards positive potential as it acted on Pd electrode (Jaksic et al. 1993).

In order to find out a suitable positive terminal potential to investigate the HER and concurrently the hydrogen evolution efficiency of the investigated $\mathrm{Ni}-\mathrm{Cu}$ electrode, the effect of variation of potential range on the redox behaviors studied at this stage in between the potential range $-1.1 \mathrm{~V}$ to +0.4 $\mathrm{V}$ at scan rate $100 \mathrm{mV} / \mathrm{sec}$. The observed voltammograms are shown in Figure 5. It

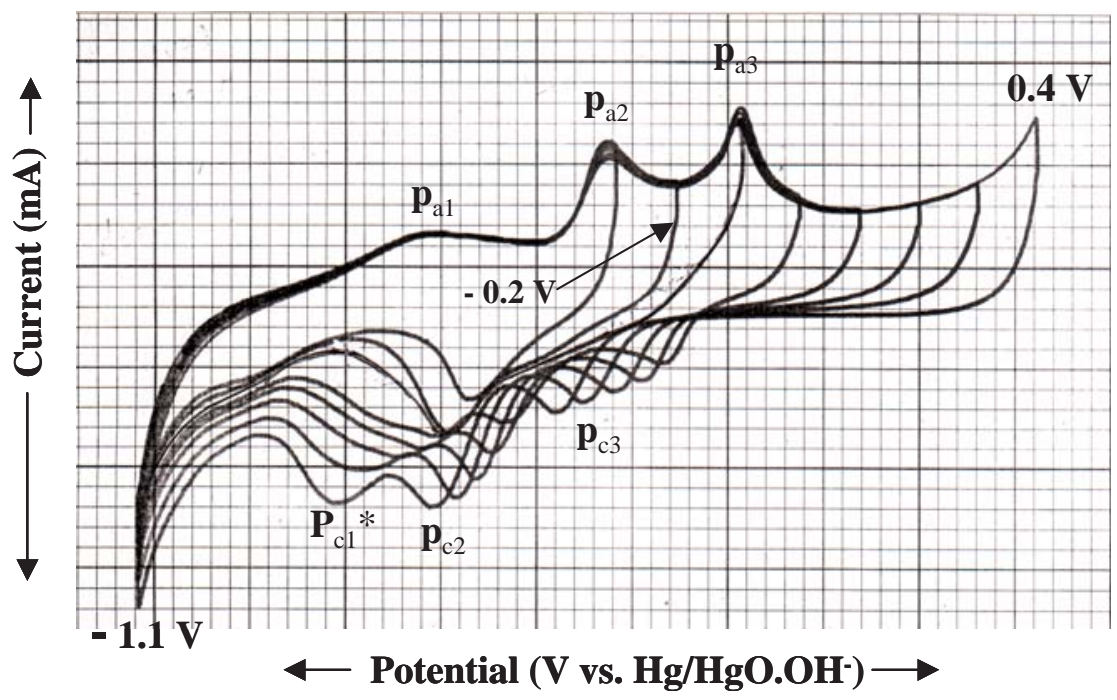

Fig. 5. Effect of potential range on the redox behavior of Ni-30at.\% $\mathrm{Cu}$ electrode in presence of further $0.04 \mathrm{~g}$ EDTA in between the potential $-1.1 \mathrm{~V}$ to $0.4 \mathrm{~V}$ at the potential scan rate 100 $\mathrm{mV} / \mathrm{s}$ after 35 minutes of cycling. 
can be seen that with the variation of potential ranges, current for $\mathrm{Ni}(0) \rightarrow \mathrm{Ni}(\mathrm{OH})_{2}$ transformation remained constant. Currents for $\mathrm{Cu}(0) \leftrightarrow \mathrm{Cu}(\mathrm{I})$ and $\mathrm{Cu}(\mathrm{I}) \leftrightarrow \mathrm{Cu}(\mathrm{OH})_{2}$ transformations decreased with decreasing the potential ranges. The voltammograms appeared up to the potential range $-1.1 \mathrm{~V}$ to $0.0 \mathrm{~V}$ showed like redox behavior. On further decrease in positive potential, the reduction peak for $\mathrm{Cu}(\mathrm{II}) \rightarrow \mathrm{Cu}(\mathrm{I})$ disappeared and that for $\mathrm{Ni}(\mathrm{OH})_{2} \rightarrow \mathrm{Ni}(0)$ came in scenario. It can be seen that $-0.2 \mathrm{~V}$ is the best anodic terminal potential because the cathodic cycle when started from this potential no noticeable hydrogen adsorption over the $\mathrm{Cu}(0)$ surface occurred to interfere the reduction step of $\mathrm{Ni}(\mathrm{OH})_{2} \rightarrow \mathrm{Ni}(0)$. Moreover, the fixing of anodic potential limit $-0.2 \mathrm{~V}$ seems suitable to achieve the predomination of $\mathrm{Ni}$ over $\mathrm{Cu}$. However, it may be seen that change in potential ranges are not contributing in hydrogen evolution efficiency. This behavior of the electrode is analogous to that observed for Ni (Jaksic et al. 1990) but quite different from those reported for Pd (Jaksic et al. 1993) and Ni-80at.\%Pd (Sarkar et al. 2008) electrodes where hydrogen evolution efficiency increased with decreasing the positive potential value in between the potential range $-1.0 \mathrm{~V}$ to $+0.75 \mathrm{~V}$.

In order to determine the hydrogen evolution efficiency and the kinetic parameters of the HER, cyclic voltammograms of Ni$30 \mathrm{at} . \% \mathrm{Cu}$ electrode were recorded in between the potential ranges $-1.4 \mathrm{~V}$ to -0.2 $\mathrm{V}$ at the potential scan rate of $10 \mathrm{mV} / \mathrm{s}$ with and without EDTA. In these cases, the electrode activation was carried out at the potential - $1.4 \mathrm{~V}$ for 30 minutes and then the

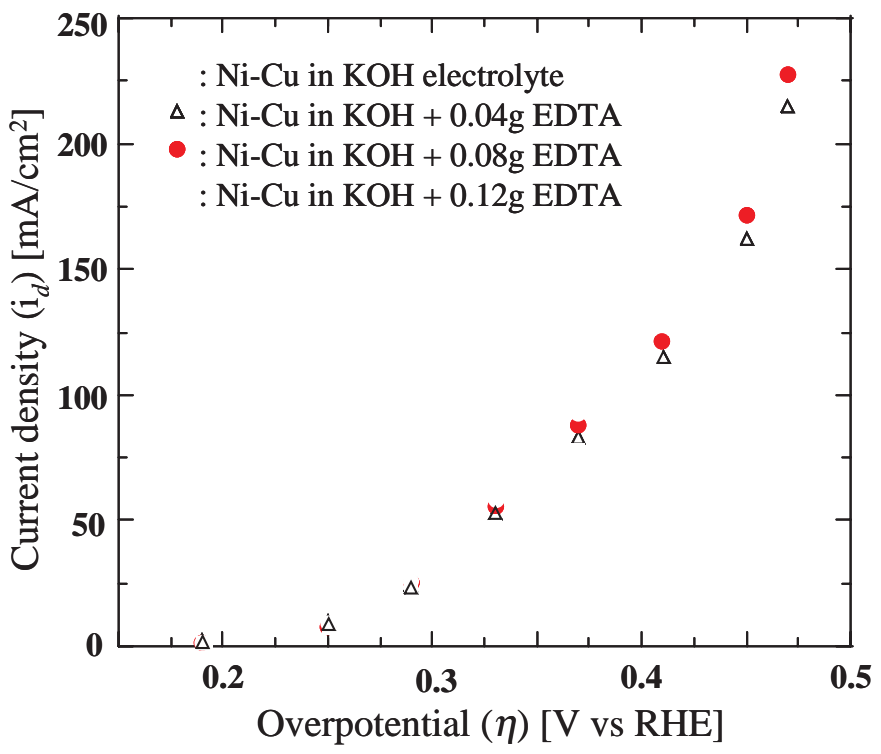

Fig. 6. Hydrogen evolution current density vs. potential relationships for the Ni-30at.\%Cu electrode with $0.04 \mathrm{~g}, 0.08 \mathrm{~g}$ and $0.12 \mathrm{~g}$ EDTA and without EDTA. 
voltammograms were recorded from the lower limit of the potential range. It was observed that hydrogen adsorption region as usually increased with increasing the negative potential value and concurrently hydrogen evolution current, i.e., hydrogen evolution efficiency gradually increased. Figure 6 shows the hydrogen evolution current density $\left(i_{d}\right)$ vs. potential relationships with $0.04 \mathrm{~g}$, $0.08 \mathrm{~g}$ and $0.12 \mathrm{~g}$ EDTA and without EDTA. It can be seen that addition of EDTA gradually increased the hydrogen evolution efficiency. Addition of 0.04g, 0.08g and 0.12g EDTA increased the hydrogen evolution efficiency about $6.3 \%, 12.4 \%$ and $17.3 \%$, respectively. The observed results are very interesting and encouraging.
In order to determine the kinetic parameters of hydrogen evolution reactions, it was necessary to draw Tafel plots. Figure 7 shows the Tafel plots (logi vs. $\eta$ values) for $0.12 \mathrm{~g}$ EDTA and without EDTA systems. It is notable that $\eta$ is equal to the difference in potentials of the working electrode and the $\mathrm{Hg} / \mathrm{HgO} . \mathrm{OH}$ - reference electrode. It can be seen that the Tafel plots show two welldefined Tafel regions as that observed for $\mathrm{Ni}$ (Kibria et al. 1995) and Ni based alloy (Giz et al. 1990). The region stands at the low overpotentials is known as low $\eta$ region. The region stands at high overpotentials is known as High $\eta$ region. The observed Tafel parameters are summarized in Table I. $b$ values are calculated from the slopes of the Tafel lines and exchange current density $\left(i_{o}\right)$ values were obtained from their extrapolation.

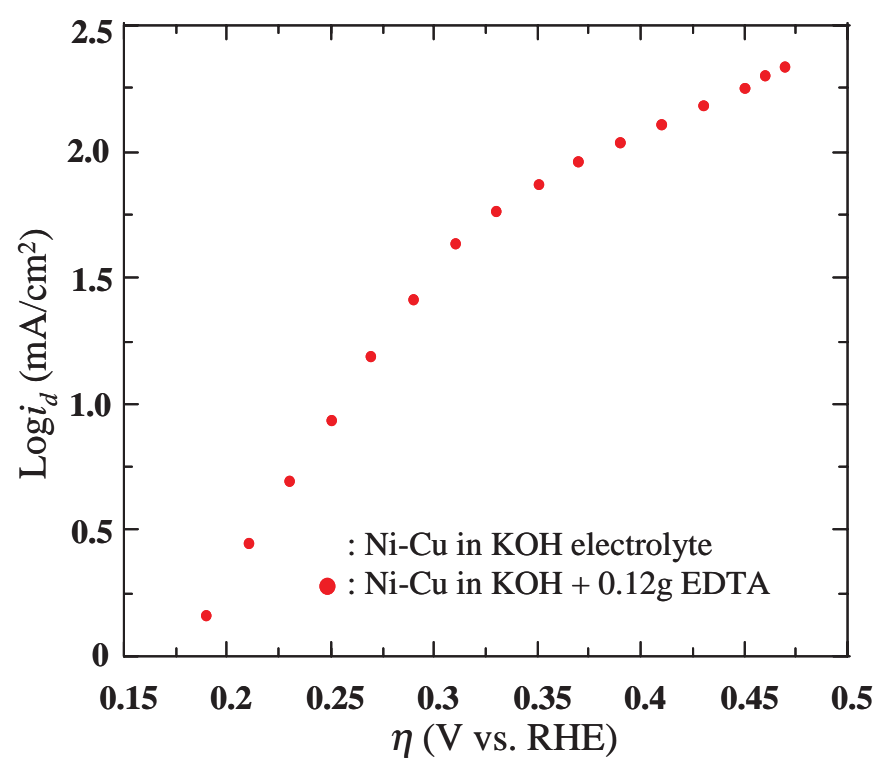

Fig. 7. Tafel plots for the hydrogen evolution reactions (HER) over Ni-30at.\% Cu electrode in $30 \mathrm{wt} . \% \mathrm{KOH}$ electrolyte in absence and presence of $0.12 \mathrm{~g}$ EDTA at room temperature. 
From the Table I, it can be seen that addition of $0.12 \mathrm{~g}$ EDTA increased the $i_{o}$ values about 1.3 times for both the Tafel regions. The observed $i_{o}$ value for the high $\eta$ region is about 1.8 and 2.9 times higher than those of $\mathrm{Ni}$ (Kibria et al. 1995) and Cu (Brossard and Marquis, 1994) electrodes. The $b$ values for both the low and high $\eta$ regions are lower than those observed for the without EDTA system and also Ni electrode (Kibria et al. 1995). From the achieved information, it can be concluded that the addition of EDTA can remarkably increase the hydrogen evolution efficiency of Ni-30at.\%Cu electrode. through water reduction. This step is known as Volmer step of electrolysis. Then two parallel competitive steps- electrochemical and chemical known as Heyrovsky step and Tafel step of electrolysis followed the Volmer step to evolve hydrogen. The reaction mechanisms can be represented as:

(i) Water reduction step (Volmer Step): $[\mathrm{Ni}-\mathrm{Cu}]+\mathrm{H}_{2} \mathrm{O}+\mathrm{e}^{-} \rightarrow[\mathrm{Ni}-\mathrm{Cu}] \mathrm{H}_{\mathrm{ads}}+\mathrm{OH}^{-}$

(ii) Electrochemical step (Heyrovsky Step): [Ni-Cu] $\mathrm{H}_{\mathrm{ads}}+\mathrm{H}_{2} \mathrm{O}+\mathrm{e}^{-} \rightarrow \mathrm{H}_{2}+$ $[\mathrm{Ni}-\mathrm{Cu}]+\mathrm{OH}^{-}$

Table I. Tafel parameters for the hydrogen evolution reactions (HER) of Ni-30at.\%Cu with and without EDTA in 30wt.\% $\mathrm{KOH}$ electrolyte at room temperature

\begin{tabular}{l|c|c|c}
\hline System & Kinetic parameters & Low $\eta$ region & High $\eta$ region \\
\hline With 0.12g EDTA & $i_{o}\left(\mathrm{~mA} / \mathrm{cm}^{2}\right)$ & $11.22 \times 10^{-3}$ & 3.55 \\
& $b(\mathrm{mV} / \mathrm{dec})$ & 84 & 260 \\
\hline Without EDTA & $i_{o}\left(\mathrm{~mA} / \mathrm{cm}^{2}\right)$ & $8.71 \times 10^{-3}$ & 2.74 \\
& $b(\mathrm{mV} / \mathrm{dec})$ & 85 & 265 \\
\hline
\end{tabular}

The observations achieved from the Figures 1-6, it is possible to propose the mechanism of the hydrogen evaluation reactions (HER) over the Ni-30at.\%Cu electrode surface. In absence and presence of EDTA, the mechanism of HER are obviously following like trends in $30 \mathrm{wt} \% \mathrm{KOH}$ electrolyte because EDTA is only cleaning the electrode surface by forming complex. It seems that HER proceeded via three important steps. The first step is the adsorption of atomic hydrogen over the Ni-30at.\%Cu electrode surface (iii) Chemical step (Tafel Step): $[\mathrm{Ni}-\mathrm{Cu}] \mathrm{H}_{\mathrm{ads}} \rightarrow[\mathrm{Ni}-\mathrm{Cu}]+\mathrm{H}_{2}$

\section{References}

Aki, H. Yamamoto, S. Kongoh, J. Maeda, T. Yamaguchi, H. Murata, A. Ishii, J. (2006) Fuel cells and energy networks of electricity, heat and hydrogen in residential area. Int. J. Hydrogen Energy 31: 967-980.

Brossard, L. Marquis, B. (1994) Electrocatalytic behavior of $\mathrm{Co} / \mathrm{Cu}$ electrodeposits in $1 \mathrm{M}$ 
$\mathrm{KOH}$ at $30^{\circ} \mathrm{C}$. Int. J. Hydrogen Energy 19 (3): 231-237.

Chi, B. Lin, H. Li, J. Wang N. Yang, J. (2006) Comparison of three preparation methods of $\mathrm{NiCo}_{2} \mathrm{O}_{4}$ electrodes. Int. J. Hydrogen Energy 31: 1210-1214.

Choquette, Y. Brossard, L. Laisa, A. Menard, H. (1990) Investigation of hydrogen evolution on raney-nickel composite-coated electrodes. Electrochemica Acta 35(8): 12511256.

Giz, M.J. Silva, J.C.P. Ferreira, M. Machado, S. A.S. Ticianelli, E.A. Avaca, L.A. Gonzalez, E. R. (1990) Progress on the development of activated cathodes for water electrolysis. Hydrogen Energy Progress 8 (1): 405-414.

Hu, C.C. Wu, Y.R. (1993) Bipolar performance of the electroplated Fe-Ni deposits for water electrolysis. Materials Chemistry and Phys., 82(3): 588-596.

Huot, J.Y. Brossard, L. (1987) Time dependence of the hydrogen discharge at $70^{\circ} \mathrm{C}$ on nickel cathodes. Int. J. Hydrogen Energy 12(12): 821-830.

Jaksic, J.M. Krstajic, N.V. Grgur, B.N. Jaksic M. M. (1998) Hydridic and electrocatalytic properties of hypo-hyper-delectronic combinations of transition metal intermetallic phases. Int. J. Hydrogen Energy 23(8): 667681.
Jaksic, M.M. Johansen, B. Ristic, M. Tunold, R. (1990) Electrocatalytic in situ activation of noble metals for hydrogen evolution, Hydrogen Energy Progress 8 (1): 461-472.

Jaksic, M.M. Johansen, B. Tunold, R. (1993) Electrochemical behavior of $\mathrm{Pd}$ in acidic and alkaline solutions of heavy and regular water. Int. J. Hydrogen Energy 18(2): 111124.

Kaninski, M.P.M. Stojic, D.L. Saponjic, D.P. Potkonjak, N.I. Miljannic, S.S. (2006) Comparison of different electrode materials: Energy requirements in the electrolytic hydrogen evolution process. J. Power sources 157 (2): 758-764.

Kibria, M.F. Mridha, M. Sh. Khan, A.H. (1995). Electrochemical studies of a nickel electrode for the hydrogen evolution reaction. Int. J. Hydrogen Energy 20(6): 435-440.

Kibria, M.F. Mridha, M.Sh. (1996). Electrochemical studies of the nickel electrode for the oxygen evolution reaction. Int. J. Hydrogen Energy 21(3): 179-182.

Kreuter, W. Hofman, H. (1998) Electrolysis: The important energy transformer in a world of sustainable energy. Int. J. Hydrogen Energy 22 (8): 661-666.

Kreysa, G. Haklansson, B. (1986) Electrolysis by amorphous metals of hydrogen and oxygen evolution in alkaline solution. $J$. Electroanal. Chem., 201(1): 61-83. 
Periasamy, P. Babu, B.R. Iyer, S.V. (1996) Cyclic voltammetric studies of porous iron electrodes in alkaline solutions used for alkaline batteries. J. Power Sources 58: 35-40.

Raj, A.I. Venkatesan, V.K. (1988) Characterization of nickel-molybdenum and nickel-molybdenum-iron alloy coatings as cathodes for alkaline water electrolysers. Int. J. Hydrogen Energy 13(4): 215-223.
Sarkar, M. Molla, A.S.I. Islam, R. Ahmed, S. Kibria, A.K.M.F. (2008) Investigations on the redox behavior and the electrolysis characteristics of Pd-20at.\%Ni electrode in 30wt.\%KOH electrolyte, Bangladesh J. Sci. Ind. Res., 43(1): 13-28.

Vandeberg, P. J. Johnson, D.C. (1993) A study of the voltammetric response of thiourea and ethylene thiourea at gold electrodes in alkaline media. J. Electroanal. Chem., 362: 129139.

Received : January 10, 2008;

Accepted : February 25, 2008; 